\title{
Endoscopic submucosal dissection for early esophageal and gastric neoplasia in decompensated cirrhosis with varices
}

Endoscopic management of gastrointestinal (GI) neoplasia in cirrhosis is challenging. Such patients are often poor candidates for surgery, yet their untreated cancer may preclude them from undergoing liver transplantation. Endoscopic submucosal dissection (ESD) offers curative resection but can be difficult in the setting of portal hypertension. Variceal band ligation may cause scarring that complicates esophageal ESD [1]. Pre-ESD transjugular intrahepatic portosystemic shunting carries procedural and hepatic encephalopathy risks. There are increasing data on the safety of endoscopic resection in patients with cirrhosis [2].

Case 1: A 62-year-old man with decompensated cirrhosis underwent endoscopy demonstrating grade II varices and
Barrett's esophagus (C6M6), with a prominent 2-cm nodule (histology: adenocarcinoma) and multifocal nodularity (high grade dysplasia) with no other medical comorbidities ( $\triangleright$ Fig. 1). A 7-cm circumferential ESD was performed. Large varices were encountered in the submucosa during dissection and were obliterated with electrocautery using Coagrasper forceps. Histology revealed intramucosal carcinoma.

Case 2: An 80-year-old woman with decompensated cirrhosis underwent upper Gl endoscopy with esophageal variceal banding. An irregular area was incidentally noted in the stomach, biopsies of which showed adenocarcinoma. The patient otherwise was in excellent overall health. ESD was performed on a 50-mm well demarcated lesion in the gastric body. Significant intraprocedural bleeding was encountered and was treated successfully with Coagrasper forceps, diluted epinephrine, and hemoclips. Histology revealed intramucosal adenocarcinoma ( $\triangleright$ Video 1 ) .

There are limited reports on esophageal $[3,4]$ and gastric ESD [5] in patients with cirrhosis. We present the first case of circumferential esophageal ESD with direct variceal obliteration and the first reported Western case of gastric ESD in decompensated cirrhosis. Both patients underwent curative resections without adverse events, demonstrating the safety and effectiveness of ESD in patients with portal hypertension and varices.
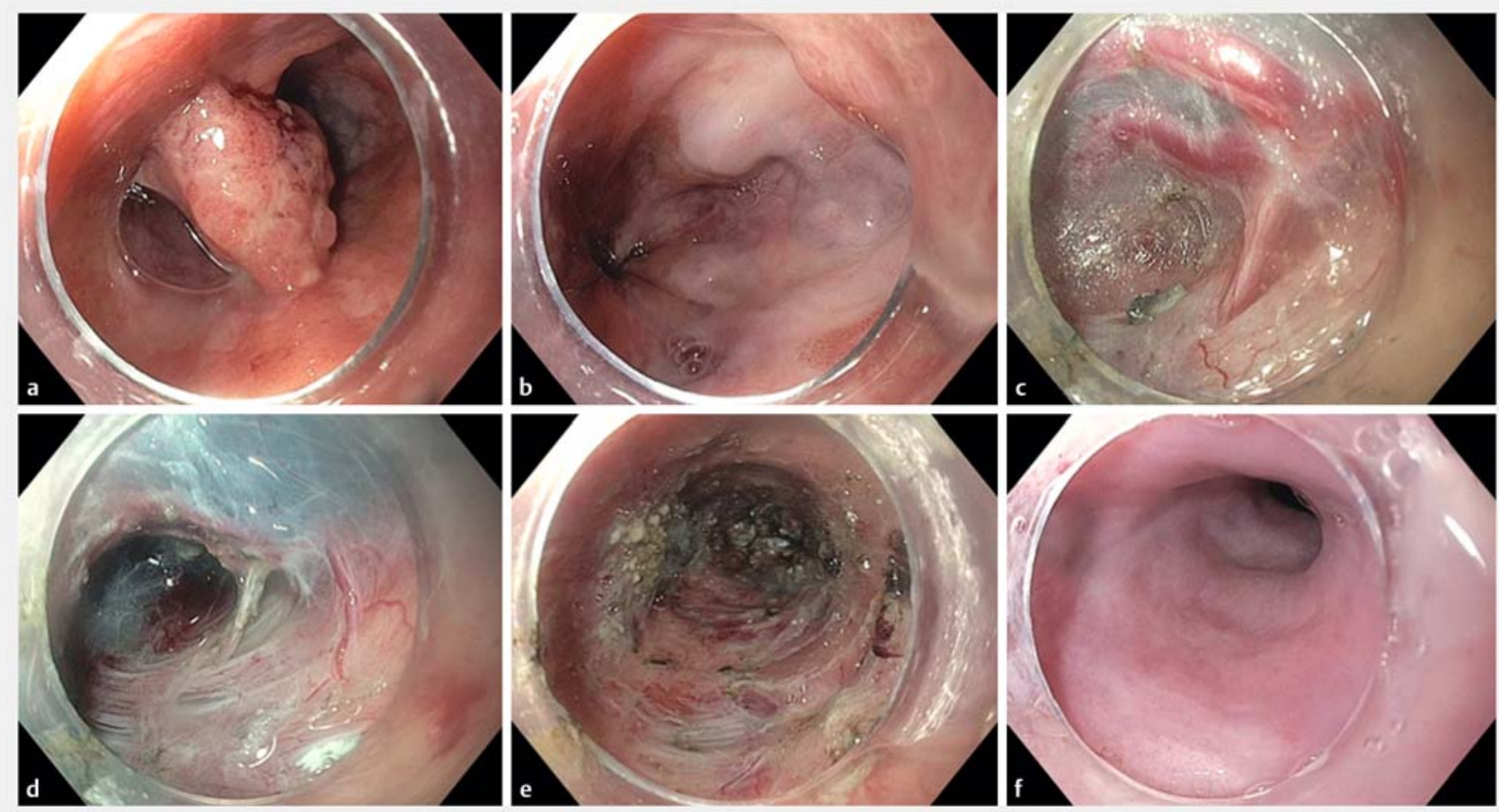

- Fig. 1 Endoscopic images of circumferential endoscopic submucosal dissection (ESD) and treatment of esophageal varices showing: a Barret's esophagus (C6M6), with a 2-cm nodule and multifocal nodularity; b scarring from previous banding and grade II esophageal varices;

c a large plexus of submucosal varices encountered during dissection; $\mathbf{d}$ appearance after direct obliteration of the submucosal varices with Coagrasper forceps, leaving the vessels deflated; e appearance after a $7-\mathrm{cm}$ circumferential ESD; $\mathbf{f}$ the healed resection site with new squamous mucosa and mild asymptomatic luminal narrowing at repeat endoscopy 5 months later. 


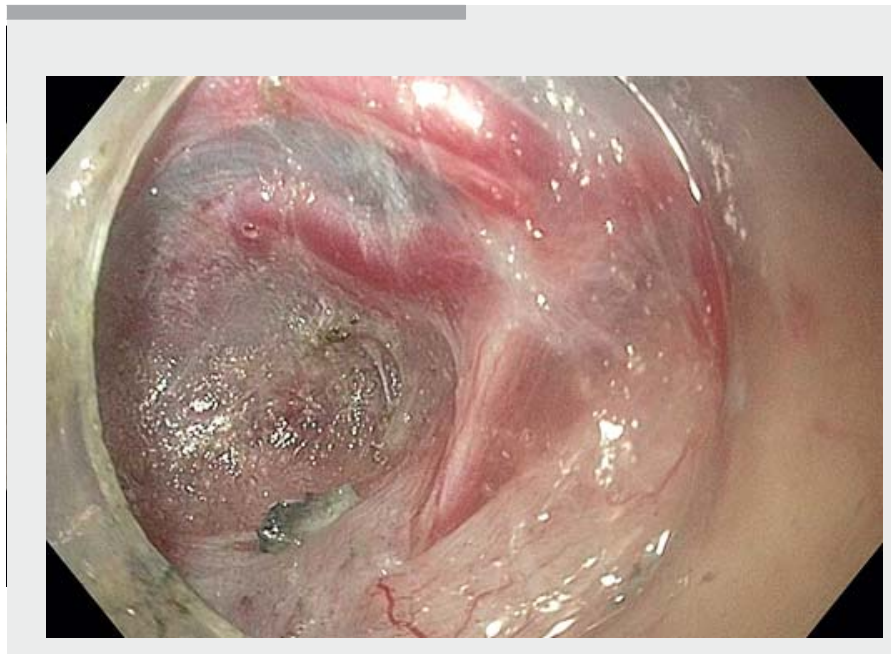

Video 1 Circumferential endoscopic submucosal dissection of Barrett's esophagusrelated neoplasia with direct obliteration of esophageal varices and endoscopic submucosal dissection of gastric adenocarcinoma in patients with cirrhosis.

Endoscopy_UCTN_Code_TTT_1AO_2AG

\section{Acknowledgments}

J.M. Kolb is supported in part by the National Institutes of Health (NIH): T32-DK007038.

\section{Competing interests}

S. Wani is a consultant for Medtronic, Boston Scientific, and Interpace. R. Soetikno is a consultant for Olympus and Fujifilm. H. Hammad is a consultant for Olympus, Medtronic, and Cook Medical. The remaining authors declare that they have no conflict of interest.

\section{The authors}

Jennifer M. Kolb ${ }^{1}$, Sachin Wani ${ }^{1}$, Roy Soetikno ${ }^{2}$, Steven A. Edmundowicz ${ }^{1}$, Hazem Hammad'

1 Division of Gastroenterology and Hepatology, University of Colorado Anschutz Medical Campus, Aurora, Colorado, USA

2 Division of Gastroenterology and Hepatology, San Francisco Veterans Affairs Medical Center, San Francisco, California, USA

\section{Corresponding author}

\section{Hazem Hammad, MD}

Division of Gastroenterology and Hepatology, University of Colorado, 1635

Aurora Court, F735, Aurora, CO 80045, USA

hazem.hammad@cuanschutz.edu

\section{References}

[1] Xu ZG, Zhao YB, Yu J et al. Novel endoscopic treatment strategy for early esophageal cancer in cirrhotic patients with esophageal varices. Oncol Lett 2019; 18: 2560-2567

[2] Miaglia C, Guillaud O, Rivory J et al. Safe and effective digestive endoscopic resection in patients with cirrhosis: a single-center experience. Endoscopy 2020. doi:10.1055/a1089-9459

[3] Wang AY, Smith EZ, Sauer BG et al. A pilot experience of endoscopic submucosal dissection of Barrett's dysplasia despite esophageal varices and decompensated cirrhosis. Hepatology 2019; 70: 2225-2227

[4] Ueda C, Yosizaki T, Katayama N et al. Barrett's adenocarcinoma with esophageal varices successfully treated by endoscopic submucosal dissection with direct varices coagulation. Clin J Gastroenterol 2019. doi:10.1007/s12328-019-01048-9

[5] Choe WH, Kim JH, Park JH et al. Endoscopic submucosal dissection of early gastric cancer in patients with liver cirrhosis. Dig Dis Sci 2018; 63: 466-473
Bibliography

Endoscopy 2021; 53: E128-E129

DOI 10.1055/a-1216-0148

ISSN 0013-726X

published online 5.8.2020

(C) 2020. Thieme. All rights reserved.

Georg Thieme Verlag KG, Rüdigerstraße 14 , 70469 Stuttgart, Germany

\section{ENDOSCOPY E-VIDEOS}

https://eref.thieme.de/e-videos

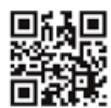

Endoscopy E-Videos is a free access online section, reporting on interesting cases and new techniques in gastroenterological endoscopy. All papers include a high quality video and all contributions are freely accessible online.

This section has its own submission website at https://mc.manuscriptcentral.com/e-videos 